\title{
Understanding How the Nephron Concentrates Urea in Urine: An Experimental Approach Using Dialysis Bags \\ Lisa M. Danish
}

\section{Nazareth College}

\section{Introduction}

- Nephron's multiple sections are differentially permeable to water and salt.

- Normal urea concentration in the blood is $2.5-7.1 \mathrm{mM}$, while it is $342-490 \mathrm{mM}$ in the urine (a hundred fold difference).

- Students struggle to understand how urea can become so concentrated.

- Simple rules of diffusion/osmosis are followed.

- Salt concentration is higher in the medullae than the cortex.

- This sets up different concentration gradients within the kidney.

- As a result, more reliance on passive transport (no energy needed)

\section{Objectives for Students}

Understanding how urea becomes concentrated

- The nephron is not permeable to urea (mostly).

- Water (and thus volume) is lost from the filtrate when the filtrate moves towards the medulla. - Reducing volume is key to concentrating urea in urine.

- Salt is lost from the filtrate when the filtrate moves towards the cortex.

- Salt goes into the medulla, increasing salt concentration there and driving passive transport, allowing water and salt to be removed from the filtrate.

\section{Methods}

- Since salt can move through the dialysis bag, sugar is used instead when salt should not be able to get though the bag.

- Urea is hypothetical, starting at $1 \%$.

- Students are asked to predict movement of molecules and changes in concentration, using a diagram:

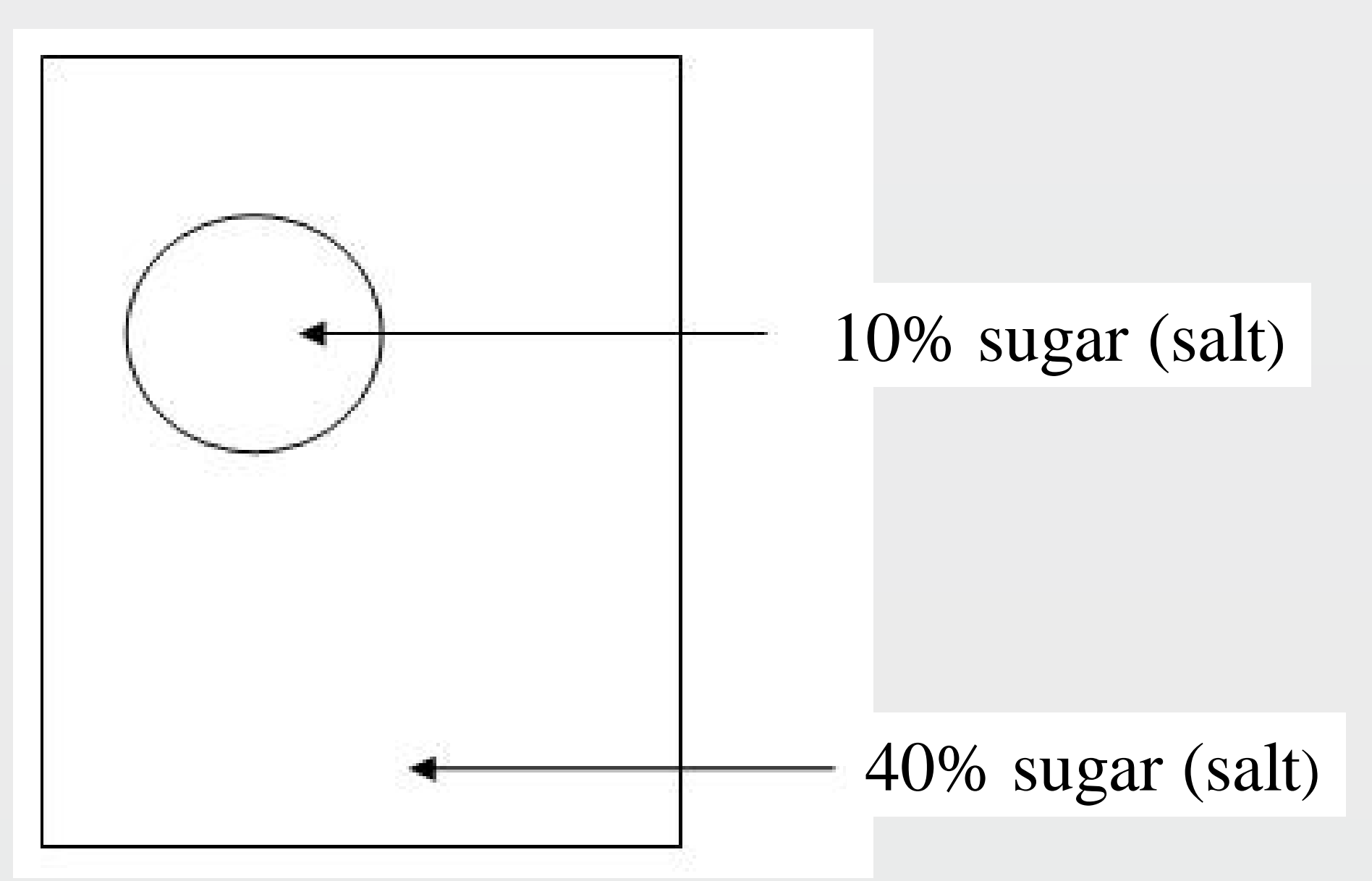

\section{Bag 1: Descending Loop of Henle}

- Permeable to water, but not salt.

- Starts at $10 \mathrm{~mL}$ water, $10 \%$ sugar (salt), $1 \%$ urea (hypothetical) in dialysis bag.

- Placed in beaker of $40 \%$ sugar for 20 minutes.

- Measure new volume, use $\mathrm{C}_{1} \mathrm{~V}_{1}=\mathrm{C}_{2} \mathrm{~V}_{2}$ to determine new concentrations for urea and salt.

Bag 2: Ascending Loop of Henle

- Permeable to salt, but not water.

- Starts with dialysis bag $\mathrm{V}_{2}$ at $\mathrm{C}_{2}$ of salt.

- Placed in beaker of $100 \% \mathrm{dH}_{2} \mathrm{O}$ for 20 minutes.

- Volume stays the same, use Conductivity Probe to determine new concentration of salt.

Bag 3: First Part of Collection Duct

- Permeable to salt, not water

- Starts with dialysis bag as Bag 2 (after), run the same as Bag 2.

\section{Bag 4: Second Part of Collection Duct}

- Permeable to water, but not salt

- Starts with dialysis bag as Bag 3 (after) run the same as Bag 1.

\section{Sample Results}

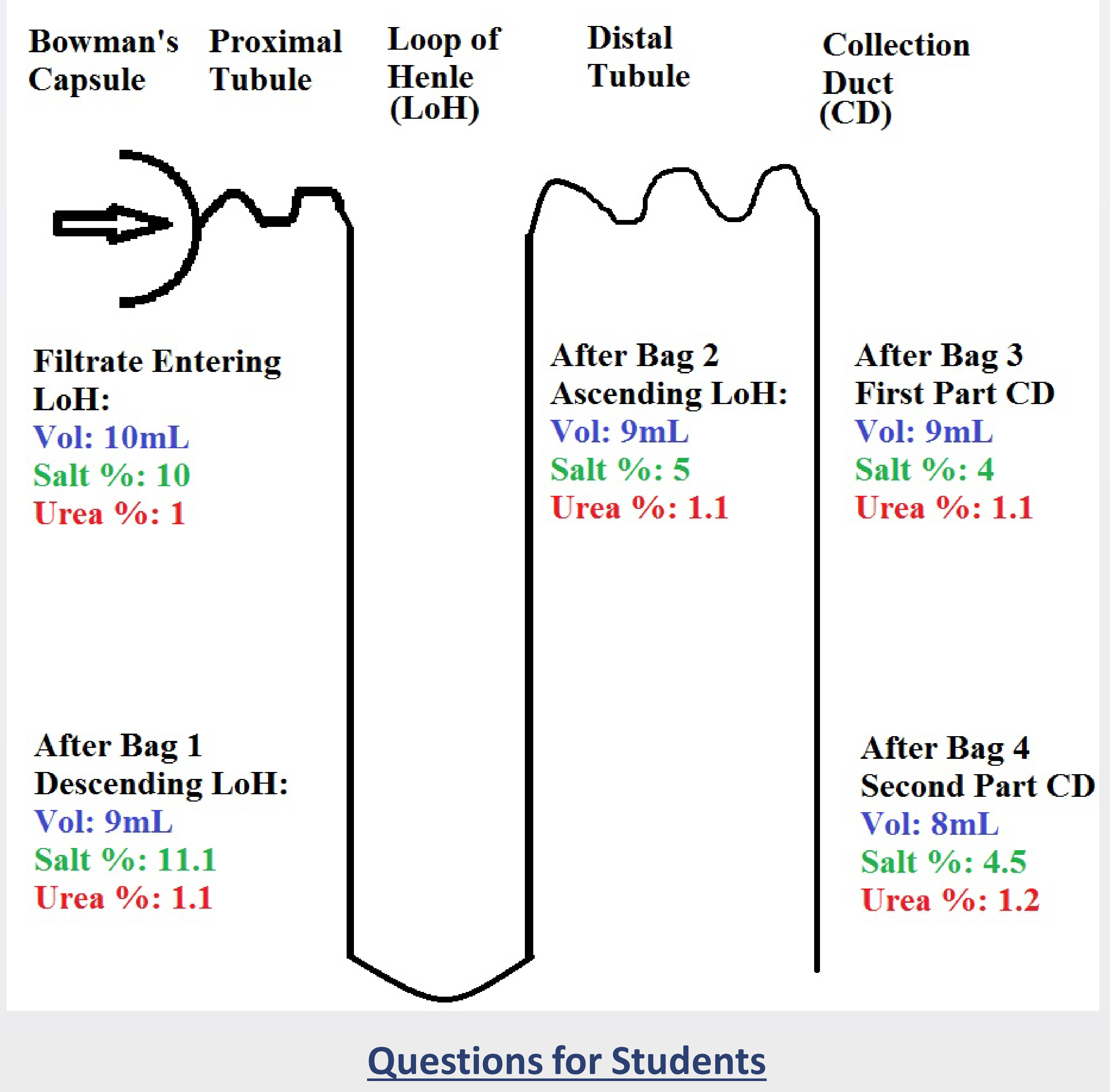

- When salt leaves the Ascending Loop of Henle (Bag 2), where does it go? How does this help maintain the different salt concentrations of the medulla and cortex?

- Explain how changing volume of water and salt results in an increasing concentration of urea as the experiment proceeds.

\section{Future Directions}

- Adding a colored dye for urea

- Including proximal and distal tubules (as calculations). 